\title{
Analysis of variable genomic loci in white spot syndrome virus to predict its origins in Procambarus clarkii crayfish farmed in China
}

\author{
Wei Zeng ${ }^{2}$, Yong Zeng ${ }^{1, *}$, Rong-Mei Fei ${ }^{3}$, Ling-Bing Zeng ${ }^{4}$, Kai-Jin Wei ${ }^{4}$ \\ ${ }^{1}$ College of Chemistry and Biology, Yantai University, Shandong 264005, PR China \\ ${ }^{2}$ No. 2 High School of Yantai, Shandong 264000, PR China \\ ${ }^{3}$ College of Veterinary Medicine, Nanjing Agricultural University, Nanjing 210095, PR China \\ ${ }^{4}$ Yangtze River Fisheries Research Institute, Chinese Academy of Fishery Sciences, Jingzhou, Hubei 434000, PR China
}

\begin{abstract}
Variable genomic loci were examined in 4 white spot syndrome virus (WSSV) isolates (08HB, 09HB, 08JS and 09JS) from Procambarus clarkii crayfish collected from Jiangsu and Hubei Provinces in China in 2008 and 2009. In ORF75, sequence variation detected in the 4 isolates, as well as in isolates sequenced previously, suggested that WSSV might have segregated into 2 lineages since first emerging as a serious pathogen of farmed shrimp in East Asia in the early-mid 1990s, with one lineage remaining in East Asia and the other separating to South Asia. In ORF23/24, deletions of 9.31, 10.97, or $11.09 \mathrm{~kb}$ were evident compared to a reference isolate from Taiwan (WSSV-TW), and, in ORF14/15, deletions of 5.14 or $5.95 \mathrm{~kb}$ were evident compared to a reference isolate from Thailand with the largest genome size (TH-96-II). With respect to these genome characteristics, the crayfish isolates $08 \mathrm{HB}, 09 \mathrm{HB}$ and $08 \mathrm{JS}$ were similar to WSSV-TW and the isolate 09JS was similar to a reference isolate from China (WSSV-CN). In addition to these loci, sequence variation was evident in ORF94 and ORF125 that might be useful for differentiating isolates and in epidemiological tracing of WSSV spread in crayfish farmed in China. However, as all 4 crayfish isolates possessed a Homologous Region 9 sequence identical to isolate WSSV-TW and another Thailand isolate (WSSV-TH), and as their transposase sequence was identical to isolates WSSV-CN and WSSV-TH, these 2 loci were not useful in predicting their origins.
\end{abstract}

KEY WORDS: White spot syndrome virus $\cdot$ Crayfish $\cdot$ Variable genomic loci $\cdot$ Spread

\section{INTRODUCTION}

White spot syndrome virus (WSSV) was first discovered in shrimp in Taiwan and China and has subsequently become widely distributed in most shrimpfarming regions of the world (Chen 1995). The virus has a broad host range, and $>90$ arthropod species including crabs, lobsters and penaeid and non-penaeid shrimp have been found to be susceptible to infection (Hossain et al. 2001, Vijayan et al. 2005, Sánchez-Paz 2010).

Complete genome sequences have been reported for 3 WSSV isolates originating from shrimp farmed in southern Taiwan in 1994 (WSSV-TW, GenBank Acc. No. AF440570; Wang et al. 2000); Suratthan, Thailand, in 1996 (WSSV-TH, Acc. No. AF369029; van Hulten \& Valk 2001); and Tongan, Xiamen, East China, in 1996 (WSSV-CN, Acc. No. AF332093; Yang et al. 2001). Although overall nucleotide sequence identity amongst the 3 genomes is high $(99.32 \%)$, single nucleotide mutations and deletions/insertions, a variable region prone to recombination, variation in the number of repeat units within hrs and direct repeats, a $13 \mathrm{~kb}$ deletion in WSSV-TH and a transposase sequence unique to WSSV-TW were identified in genome-sequenced comparisons (Marks et al. 
2004). Some of the loci displaying variability have been exploited as epidemiological tools to track the spread of WSSV in shrimp farmed in Vietnam (Dieu et al. 2004). From the data, it was evident that the WSSV types that emerged in Vietnam shared a common lineage with Thai WSSV types, had digressed from lineages found in Taiwan and China, and were likely to have been derived from multiple introduction events. Similar analysis of the ORF14/15 and ORF23/24 variable regions in $81 \mathrm{WSSV}$ isolates from India showed them to be the major polymorphic loci, and indicated that the Indian isolates were likely to have originated from Thailand (Pradeep et al. 2008). Another study demonstrated that variable-number tandem-repeat (VNTR) sequences in ORF75 and ORF125 were also useful markers for examining interregional spread of WSSV (Dieu et al. 2004, 2010).

Red swamp crayfish Procambarus clarkii is a native species of China often used experimentally to examine the pathogenesis of WSSV (Wei et al. 1998, van Hulten \& Valk 2001, Zhu \& Lu 2001, Du et al. 2006, 2007, Li et al. 2006, Zeng \& Lu 2009). Due to increased domestic and export demand, $P$. clarkii is now cultured widely in China, with yields reaching $\sim 4.8 \times 10^{5}$ tons in 2009. In 2007, WSSV was first reported in P. clarkii farmed in China (Wang et al. 2007), and since then white spot disease (WSD) has become a major problem for the crayfish-farming industry (Ding et al. 2008, Xu et al. 2008, Liang et al. 2010). It is interesting that whilst WSD spread rapidly and widely elsewhere, with reports of it occurring in freshwater crayfish and cultured stocks of Penaeus vannamei, P. stylirostris and $P$. setiferus in the USA as early as 1995 (Lightner et al. 1997, Richman et al. 1997), outbreaks in P. clarkii farmed in China were delayed by some $15 \mathrm{yr}$ after WSSV first impacted the local penaeid shrimp culture industry. As variations in pathogenicity and viral protein profiles have also been detected amongst WSSV isolates originating from different hosts (Wang et al. 1999, 2000, Waikhom et al. 2006), analysis of variable genomic loci to determine the genetic relatedness of WSSV types derived from crayfish and shrimp should shed light on its origins and the dissemination mechanisms potentially useful in defining disease control strategies.

Here a number of variable genomic loci were examined in 4 WSSV isolates originating from diseased Procambarus clarkii collected from farms in the Jiangsu and Hubei Provinces of China in 2008 and 2009. Sequence variations detected amongst the $P$. clarkii WSSV isolates and against reference WSSV isolates from penaeid shrimp originating from Taiwan, China and Thailand were used to assess the epidemiological value of each marker and to predict the origins of the $P$. clarkia WSSV isolates.

\section{MATERIALS AND METHODS}

Crayfish. Procambarus clarkii crayfish displaying signs of WSD were collected from farms in the Jiangsu and Hubei Provinces of China in 2008 and 2009 (Fig. 1). Crayfish were transported to the laboratory at Yantai University in ice boxes and stored at $-40^{\circ} \mathrm{C}$ until used.

DNA extraction. Gill tissue (100 mg) from individual crayfish was homogenized in $0.4 \mathrm{ml}$ Proteinase $\mathrm{K}$ buffer (10 mM Tris-HCl pH 7.8, 5 mM EDTA, 0.5\% SDS) in a sterile $1.5 \mathrm{ml}$ microcentrifuge tube using a disposable tissue-grinding pestle followed by the addition of $1 \mu \mathrm{l}$ of $20 \mathrm{mg} \mathrm{ml}^{-1}$ Proteinase $\mathrm{K}$ and overnight incubation at $55^{\circ} \mathrm{C}$. Total DNA was then extracted using a standard phenol-chloroform method, precipitated under ethanol overnight at $-20^{\circ} \mathrm{C}$ and recovered by centrifugation at $15000 \times \mathrm{g}$ for $10 \mathrm{~min}$ at $4^{\circ} \mathrm{C}$. The DNA pellet was dissolved in $30 \mu \mathrm{l}$ TE buffer $(10 \mathrm{mM}$ Tris- $\mathrm{HCl} \mathrm{pH}$ 8.0, 1 mM EDTA) for testing with polymerase chain reaction (PCR) method.

PCR. PCR primers designed for the highly conserved VP28 gene sequence were used to amplify WSSV DNA (Marks et al. 2004). PCR primers designed to amplify across various variable genome regions were as described elsewhere (Dieu et al. 2004, Marks et al. 2005). DNA extracted from crayfish infected experimentally with WSSV was used as a positive control, and PCR-grade water was used as a negative control. PCR primer sequences and annealing temperatures, PCR extension times and expected amplicon lengths are shown in Table 1.

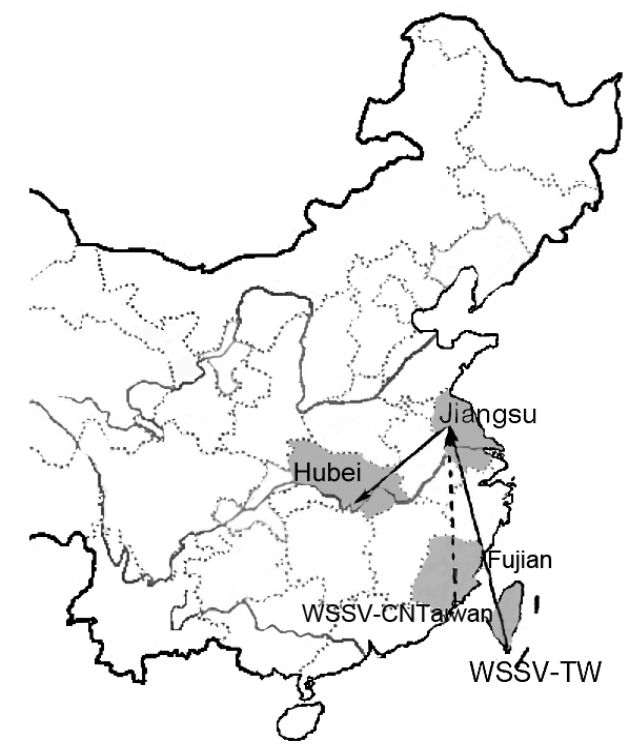

Fig. 1. Eastern China, showing the geographical origins of the white spot syndrome virus (WSSV) isolates used in the present study. Solid-lined arrows show the origin of isolates 08JS, 08HB and 09HB; broken-lined arrow shows the origin of isolate 09JS 
Table 1. PCR primers used to detect and amplify variable loci of white spot syndrome virus (WSSV)

\begin{tabular}{|c|c|c|c|c|c|}
\hline Primer & Sequence $\left(5^{\prime}-3^{\prime}\right)$ & $\begin{array}{c}\text { Annealing } \\
\text { temperature }\left({ }^{\circ} \mathrm{C}\right)\end{array}$ & $\begin{array}{l}\text { Elongation } \\
\text { time (s) }\end{array}$ & $\begin{array}{l}\text { WSSV sequence } \\
\text { coordinates }\end{array}$ & $\begin{array}{l}\text { PCR product } \\
\text { size (bp) }\end{array}$ \\
\hline \multicolumn{6}{|l|}{ WSSV detection } \\
\hline VP28F & СТTTСТTTCAСТСТTTCGT & \multirow[t]{2}{*}{50} & \multirow[t]{2}{*}{60} & $7-25^{\mathrm{a}}$ & \multirow[t]{2}{*}{600} \\
\hline VP28R & CTCAGTGCCAGAGTAGGT & & & $606-623^{a}$ & \\
\hline \multicolumn{6}{|c|}{ WSSV variable loci } \\
\hline 14/15-screen-F & GAGATGCGAACCACTAAAAG & \multirow[t]{2}{*}{49} & \multirow[t]{2}{*}{75} & $22904-22923^{a}$ & \multirow[t]{2}{*}{1254} \\
\hline 14/15-screen-R & ATGGAGGCGAGACTTGC & & & $24157-24141^{\mathrm{a}}$ & \\
\hline $23 / 24 \mathrm{AFF}$ & TCTTCСТАTTTCGTTTCCAT & \multirow[t]{2}{*}{50} & \multirow[t]{2}{*}{120} & $3158-3177^{\mathrm{b}}$ & \multirow[t]{2}{*}{12386} \\
\hline 23/24BRR & АТТTССТССАТТТСТТТСТС & & & $15543-15524^{\mathrm{b}}$ & \\
\hline $23 / 24 \mathrm{CFF}$ & GAATGGGCTCTGCTAACT & \multirow[t]{2}{*}{50} & \multirow[t]{2}{*}{120} & $4357-4374^{\mathrm{b}}$ & \multirow[t]{2}{*}{11187} \\
\hline 23/24BRR & АТТТССТССАТТТСТТТСТС & & & $15543-15524^{\mathrm{b}}$ & \\
\hline ORF75-flank-F & GAAGCAGTATCTCTAACAC & \multirow[t]{2}{*}{49} & \multirow[t]{2}{*}{80} & $107875-107893^{\mathrm{a}}$ & \multirow[t]{2}{*}{868} \\
\hline ORF75-flank-R & CAACAGGTGCGTAAAAGAAG & & & $108742-108723^{a}$ & \\
\hline ORF94-flank-F & GTGCCGCAGGTCTACTC & \multirow[t]{2}{*}{51} & \multirow[t]{2}{*}{80} & $142656-142672^{\mathrm{a}}$ & \multirow[t]{2}{*}{682} \\
\hline ORF94-flank-R & CATACGACTCTGCTTCTTG & & & $143337-143319^{a}$ & \\
\hline ORF125-flank-F & CGAAATCTTGATATGTTGTGC & \multirow[t]{2}{*}{52} & \multirow[t]{2}{*}{100} & $187791-187811^{\mathrm{a}}$ & \multirow[t]{2}{*}{652} \\
\hline ORF125-flank-R & CCATATCCATTGCCСТTCTC & & & $188442-188423^{a}$ & \\
\hline \multirow[t]{2}{*}{ Transposase-F } & GTGGATAATATTCGTCTTCAAC & \multirow[t]{2}{*}{55} & \multirow[t]{2}{*}{120} & $253988-254009^{a}$ & \multirow{3}{*}{$\begin{array}{c}1489^{\mathrm{b}} \\
151^{\mathrm{a}}\end{array}$} \\
\hline & & & & & \\
\hline Transposase-R & CTCAAAGACAACGACATTAG & \multirow{3}{*}{58} & \multirow{3}{*}{180} & $254138-254119^{a}$ & \\
\hline hr9-F & GGTGGGAGAGGAAGTATTATG & & & $283189-283209^{a}$ & \multirow[t]{2}{*}{2181} \\
\hline hr9-R & GTCCATATGATGATTCTCTACC & & & $285369-285348^{a}$ & \\
\hline \multicolumn{6}{|c|}{${ }^{\mathrm{a} A c c o r d i n g}$ to WSSV-TH sequence } \\
\hline
\end{tabular}

Cloning and sequencing of PCR products. PCR products were cloned into the pUCm-T vector (Sangon, Shanghai, PR China) which was transformed into Escherichia coli DH5 $\alpha$ host cells. DNA extracted from recombinant plasmids was sequenced by Shanghai Sangon Biological Engineering Technology \& Services Co. Ltd. Sequence chromatograms were analyzed using the DANSTAR 4.2 (DNASTAR Inc.) software package.

\section{RESULTS}

Of groups of 5 WSSV-infected Procambarus clarkii crayfish collected in 2008 and 2009 from WSD-affected ponds in Jiangsu and Hubei Provinces, DNA from 1 crayfish of each group (4 in total) that tested WSSVpositive by single-step PCR was chosen for further analysis. The 2008 and 2009 WSSV isolates from Jiangsu Province were designated 08JS and 09JS, respectively, and isolates from Hubei Province were designated 08HB and 09HB, respectively.

\section{Variable region ORF23/24}

Based on comparisons of the complete genome sequences of 3 reference WSSV isolates, the ORF23/24 variable region of WSSV-CN and WSSV-TH isolates possess deletions of 1.2 and $13 \mathrm{~kb}$, respectively, compared to a WSSV-TW isolate (Marks et al. 2004). From sequence analyses of ORF23/24, PCR products amplified using the primer pair 23/24AFF:23/24BRR, deletions of 11086 and $10970 \mathrm{bp}$ existed in the Procambarus clarkii WSSV isolates 08HB/09JS and 09HB, respectively, compared to WSSV-TW (Fig. 2). In order to characterize the ORF23/24 variable region in isolate 08JS, the PCR primer pair 23/24CFF:23/24BRR was used, and a deletion of $9310 \mathrm{bp}$ was detected in comparison to WSSV-TW (Fig. 2).

\section{Variable region ORF14/15}

Compared to other WSSV isolates sequenced to date, the TH-96-II isolate has a 6436 bp insertion in the ORF14/15 variable region (Marks et al. 2005). Based on this fact, it has been suggested that this genotype might represent the common ancestor of WSSV in SE Asia (Dieu et al. 2010). Sequence data generated for PCR products amplified using primer pair 14/15screen-F:14/15-screen-R identified that isolates 08HB, 09HB and 08JS shared the same sequence as WSSVTW, thus possessing a 5139 bp deletion compared to TH-96-II, and that isolate 09JS possessed a $5950 \mathrm{bp}$ deletion compared to TH-96-II (Fig. 3). 


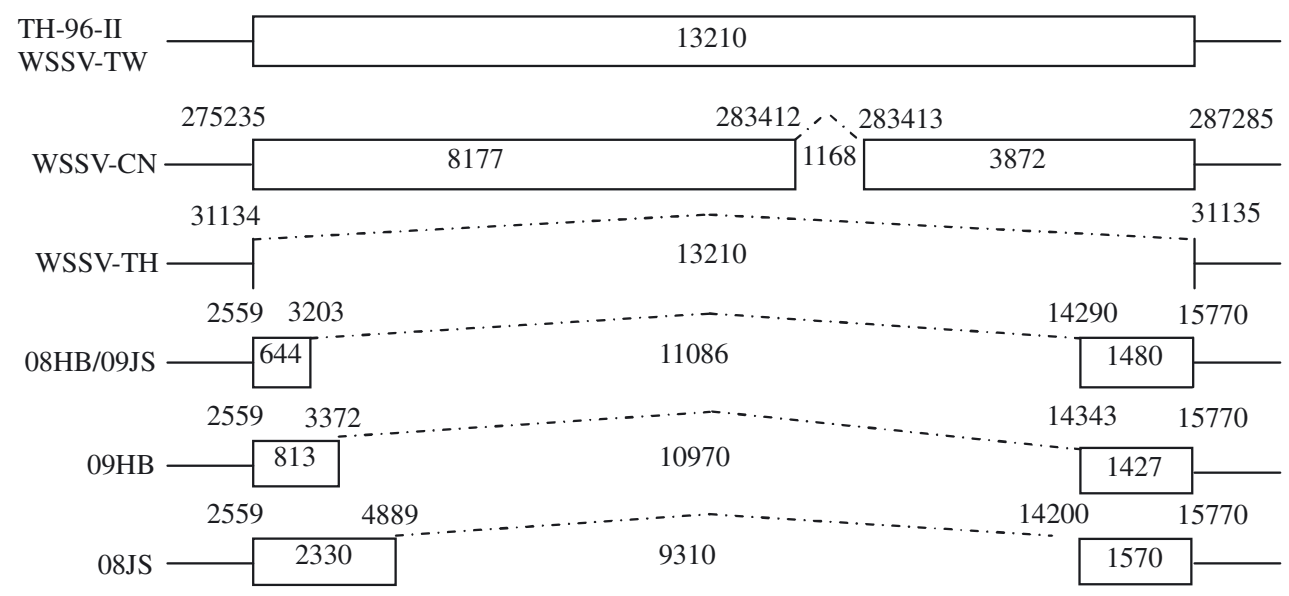

Fig. 2. Schematic representation of 'variable region ORF23/24'. The genome coordinates of crayfish Procambarus clarkii isolates are given according to annotation for WSSV-TW (GenBank Acc. No. AF440570)

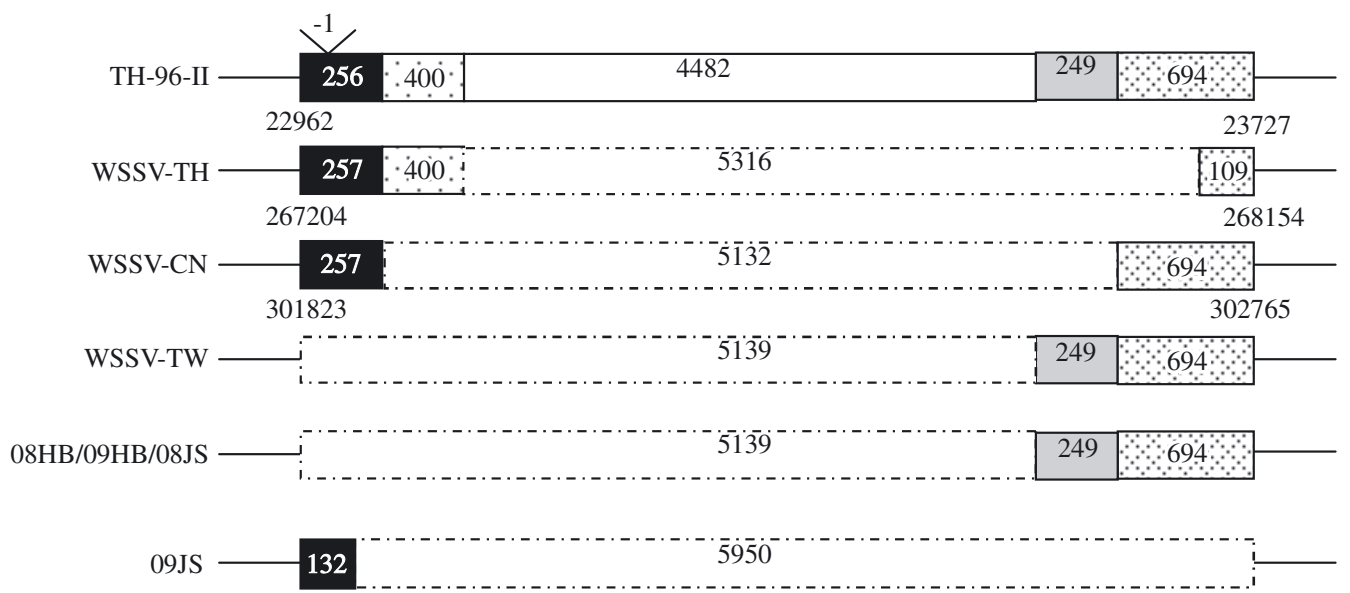

Fig. 3. Schematic representation of 'variable region ORF14/15' of crayfish Procambarus clarkii WSSV isolates compared to reference isolates. Different shadings represent unique sequences

\section{Genome region encoding a putative transposase}

PCR amplification across the putative transposase sequence unique to isolate WSSV-TW generated a 151 bp product with all 4 Procambarus clarkii isolates consistent with the sequences of isolates WSSV-CN and WSSV-TH, indicating the absence of the $1337 \mathrm{bp}$ insert present in WSSV-TW.

\section{Homologous Region 9}

In baculoviruses, homologous region (hr) sequences play a role in replicating DNA and enhancing transcription (Guarino \& Summers 1986, Kool et al. 1993). Amongst the $9 \mathrm{hr}$ sequences apparent in the genomes of WSSV-TH, WSSV-CN and WSSV-TW, 4 show differ- ences in the number of repeat units. In PCR analyses across the hr9 region, in which WSSV-CN has 1 additional repeat unit compared to WSSV-TW and WSSVTH (Marks et al. 2004), all 4 P. clarkii isolates generated a $2181 \mathrm{bp}$ product identical in length and nucleotide sequence to WSSV-TW and WSSV-TH.

\section{Genetic variation in VNTR loci}

Amongst WSSV-TH, WSSV-CN and WSSV-TW, 3 non-hr unidirectional tandem repeats located in the ORF75, ORF94 and ORF125 coding regions have been shown to possess variable repeat unit (RU) numbers (Dieu et al. 2004, Marks et al. 2004). Sequence analyses of PCR products amplified from the 4 Procambarus clarkii isolates were undertaken to examine each of these 3 loci. 
Table 2. ORF75 genotypes of crayfish Procambarus clarkii WSSV isolates compared to reference isolates. The numbers of 45 and $102 \mathrm{bp}$ repeat units (RUs) are given in parentheses. Numbers of successive tandem RUs of $45 \mathrm{bp}$ are summarized as $\mathrm{n} \times 45$. The genotypes of each $45 \mathrm{bp}$ RU at Positions 3, 15, 30, 40, 42 and 44, are TTAAAG (a), CCAGAA (b), CCAAGG (c), CCGGAA (d), CTGAGG (e), CCTAGG (f), CCAAAG (g), TTGAGG (h) and CTAAGG (i). The genotypes of each 102 bp RU at Positions 3, 15, 30 and 83, are TTGC (L), CCGC (M), CCAT (N), CCAC (O) and CCTC (P). NR: no repeat units

\begin{tabular}{|llll|}
\hline Isolate & Number & Positioning & Genotypes \\
\hline TH-96-II & $16(12,4)$ & $45,102,4 \times 45,102,2 \times 45,102,3 \times 45,102,2 \times 45$ & a-L-b-c-d-c-M-c-e-N-f-f-f-O-f-c \\
WSSV-TW & $21(17,5)$ & $45,102,4 \times 45,102,3 \times 45,102,2 \times 45,102,4 \times 45,102,2 \times 45$ & a-L-b-c-d-c-M-g-h-i-N-f-f-N-f-f-c-f-P-f-c \\
WSSV-TH & $12(9,3)$ & $45,102,4 \times 45,102,2 \times 45,102,2 \times 45$ & a-L-b-c-d-c-M-c-e-N-f-f \\
WSSV-CN & $15(1,4)$ & $45,102,4 \times 45,102,2 \times 45,102,2 \times 45,102,2 \times 45$ & a-L-b-c-d-c-M-g-h-N-f-f-P-f-c \\
08HB & NR & NR & NR \\
09HB & $5(4,1)$ & $45,102,3 \times 45$ & a-L-b-b-c \\
08JS & $13(9,4)$ & $45,102,4 \times 45,102,2 \times 45,2 \times 102,2 \times 45$ & a-L-b-c-d-c-M-g-h-N-P-f-c \\
09JS & $10(7,3)$ & $45,102,2 \times 45,102,2 \times 45,102,2 \times 45$ & a-L-b-c-M-e-f-P-f-c \\
& & & \\
\hline
\end{tabular}

ORF75. In all WSSV isolates characterized to date, ORF75 possesses concatemers comprising mixtures of 2 RU types either 45 or $102 \mathrm{bp}$ in length, with the sequence of the first $45 \mathrm{bp}$ of each $102 \mathrm{bp}$ RU being identical to the discrete $45 \mathrm{bp}$ RU (Dieu et al. 2004). Comparing all WSSV isolates reported to date, a single nuclear polymorphism (SNP) can occur at Positions 3, $15,30,40,42$ and 44 in the $45 \mathrm{bp}$ RU sequence and at Positions 3, 15, 30 and 83 in the 102 bp RU sequence. Except for isolate 08HB, the other 3 P. clarkii WSSV isolates possessed these short and long ORF75 RU types ordered and characterized as summarized in Table 2.

ORF94. In all WSSV isolates characterized to date, ORF94 has a single $54 \mathrm{bp}$ tandem RU with a SNP at Position 48 (either guanine or thymine). The number and types of the 54 bp RU detected in the 4 Procambarus clarkii WSSV isolates compared to the 3 reference WSSV isolates are summarized in Table 3.

ORF125. ORF125 contains a 69 bp tandem RU, of which the first 2 (designated A and B) and the last (designated T) can be recognized by specific SNPs compared to the intervening RUs that can occur at Positions 8, 18, 25, 66 and 69 (Dieu et al. 2004). The number and types of the $69 \mathrm{bp}$ RUs detected in PCR products amplified from the 4 Procambarus clarkii WSSV isolates compared to 3 reference isolates are summarized in Table 4 . Three of the $4 \mathrm{P}$. clarkii isolates were also noted to possess new RU types (designated G and F) not described previously.

\section{DISCUSSION}

One reason that Procambarus clarkii crayfish were initially used in China to study the characteristics and pathogenesis of WSSV was that wild local crayfish were commonly found to be free of WSSV infection (Wei et al. 1998, Zhu \& Lu 2001, Zeng \& Lu 2009). How- ever, due to consumer demand and its high commercial value, $P$. clarkii has now become an important freshwater aquaculture species farmed widely across inland China, and WSD has become a major problem for this industry (Wang et al. 2007, Ding et al. 2008, Xu et al. 2008, Liang et al. 2010). To assist in identifying the root sources of WSSV infection in crayfish farmed in China and devising strategies to control its spread

Table 3. ORF94 genotypes of crayfish Procambarus clarkii WSSV isolates compared to reference isolates. The base of each successive repeat unit at Position 48 is shown

\begin{tabular}{|lcl|}
\hline Isolate & Number & Genotypes \\
\hline TH-96-II & 6 & $\mathrm{G}, \mathrm{T}, \mathrm{G}, \mathrm{T}, \mathrm{T}, \mathrm{T}$ \\
WSSV-TW & 6 & $\mathrm{~T}, \mathrm{~T}, \mathrm{~T}, \mathrm{G}, \mathrm{T}, \mathrm{T}$ \\
WSSV-TH & 6 & $\mathrm{~T}, \mathrm{G}, \mathrm{G}, \mathrm{G}, \mathrm{T}, \mathrm{T}$ \\
WSSV-CN & 12 & T, T, G, G, G, G, G, G, T, T, T, T \\
08HB & 8 & $\mathrm{G}, \mathrm{G}, \mathrm{G}, \mathrm{T}, \mathrm{T}, \mathrm{G}, \mathrm{G}, \mathrm{T}$ \\
09HB & 14 & $\mathrm{~T}, \mathrm{~T}, \mathrm{~T}, \mathrm{~T}, \mathrm{G}, \mathrm{T}, \mathrm{T}, \mathrm{G}, \mathrm{T}, \mathrm{T}, \mathrm{T}, \mathrm{G}, \mathrm{G}, \mathrm{T}$ \\
08JS & 3 & $\mathrm{~T}, \mathrm{~T}, \mathrm{~T}$ \\
09JS & 8 & $\mathrm{G}, \mathrm{T}, \mathrm{G}, \mathrm{G}, \mathrm{T}, \mathrm{T}, \mathrm{T}, \mathrm{T}$ \\
\hline
\end{tabular}

Table 4. ORF125 genotypes of crayfish Procambarus clarkii WSSV isolates compared to reference isolates. The genotypes of each $69 \mathrm{bp}$ repeat unit at Positions 8, 18, 25, 66 and 69, respectively, are TGGTC (C), TTGGT (D), CGAGT (E), CGATC (F) and TGAGT (G). The genotypes of the first 2 RUs are defined as A and B, respectively; the last one is defined as $\mathrm{T}$

\begin{tabular}{|lcl|}
\hline Isolate & Number & Genotypes \\
\hline TH-96-II & 6 & A, B, C, D, E, T \\
WSSV-TW & 8 & A, B, C, C, C, D, E, T \\
WSSV-TH & 6 & A, B, C, D, E, T \\
WSSV-CN & 8 & A, B, C, D, C, D, D, T \\
08HB & 15 & A, B, C, G, E, E, F, C, G, E, E, E, E, F, T \\
09HB & 9 & A, B, C, G, E, E, E, E, T \\
08JS & 6 & A, B, C, G, E, T \\
09JS & 7 & A, B, C, C, D, E, T \\
\hline
\end{tabular}


and impact, molecular epidemiological studies of WSSV isolates are important.

Despite associations between the pathogenicity and protein profiles of WSSV isolates examined from different hosts (Wang et al. 1999, 2000, Waikhom et al. 2006), the factors dictating virulence are likely to be complex. Genome sequence data on WSSV isolates from different penaeid shrimp species, as well as the blue crab Callinectes sapidus, suggest they have a common recent ancestry (Chang et al. 2001, Chen et al. 2002, Moon et al. 2003, Marks et al. 2004, Dieu et al. 2004). As the hr9 sequence determined for the 4 Procambarus clarkii isolates was identical to reference WSSV-TW/WSSV-TH isolates (Wang et al. 2000, van Hulten \& Valk 2001) and as their transposase sequence was identical to reference WSSV-TH/WSSV-CN isolates (van Hulten \& Valk 2001, Yang et al. 2001), all these isolates also appear to have a common recent ancestry.

Based on sequence variations in ORF14/15 and ORF23/24, Dieu et al. (2004) proposed a model for how genotypic changes in WSSV might have progressed during its geographical spread from China and Taiwan to Thailand between 1992 and 1995. From the study of variable region genotypes of WSSV isolates from Vietnam (WSSV-VN), evidence was obtained for deletion lengths in these variable regions increasing progressively as WSSV spread and for each loci evolving independently (Dieu et al. 2004). From these data, it was deduced that the WSSV common ancestor might possess an ORF23/24 variable region genotype similar to WSSV-TW and an ORF14/15 variable region genotype with all unique sequences. The Thai WSSV isolate TH96-II, with the largest genome $(\sim 312 \mathrm{~kb})$ reported, fit both characteristics (Marks et al. 2005). Different-sized ORF14/15 and ORF23/24 deletions were found amongst the 4 Procambarus clarkii WSSV isolates, with ORF14/15 in 08HB, 09HB and 08JS being identical to the reference isolate WSSV-TW and 09JS being identical to isolates detected in penaeid shrimp from India (WSSV-IN-05), Vietnam (WSSV-VN-LA, WSSVVN-X, WSSV-VN-S), Japan (WSSV-JA), Cambodia (WSSV-CB), Thailand (WSSV-TH-S) and Iran (WSSVIR) (Dieu et al. 2010, Zwart et al. 2010). ORF23/24 of isolate 09HB was identical to isolates WSSV-IN-05, WSSV-VN-LA, WSSV-JA and WSSV-CB (Zwart et al. 2010). These sequence similarities suggest that the model proposed by Dieu et al. (2004) for analyzing the genotypic changes in WSSV from penaeid shrimp can also be used to evaluate the evolution of WSSV in freshwater crayfish. Deletions in ORF14/15 and ORF23/24 can thus be used as molecular makers to trace viral spread in freshwater crayfish.

Amongst the 4 Procambarus clarkii WSSV isolates examined, the ORF14/15 sequence in isolate 09JS was identical to isolates (WSSV-VN-X/WSSV-VN-S) representative of the genotype detected in shrimp in central Vietnam and was proposed to have originated from WSSV-CN (Dieu et al. 2010). In ORF23/24, isolate 09JS possessed a 9918 bp deletion compared to the reference isolate WSSV-CN, suggesting it might be derived from WSSV-CN. In contrast, the other 3 isolates (08JS, 08HB, 09HB) each possessed different-sized ORF23/24 deletions compared to the reference isolate WSSV-TW and an ORF14/15 sequence identical to WSSV-TW. The data suggested that isolate 08JS is a close relative of WSSV-TW and that isolates 08HB and 09HB might be recent descendents of isolate 08JS. Taken together, variation seen at these 2 loci suggest that the P. clarkii WSSV isolates originated from multiple introductions of virus types circulating in penaeid shrimp in East Asia. This is consistent with WSD outbreaks having first occurred in penaeid shrimp farmed in China $>15$ yr ago and with $P$. vannamei being cultured in freshwater in China, initially in coastal provinces, for $>10$ yr (Xu et al. 2009). The geographical location of the coastal Jiangsu and more inland Hubei Provinces in China, from which the WSSV-infected P. clarkii were obtained, also implicates the role of commercial shrimp farming in the emergence and spread of WSSV, e.g. via transportation of broodstock and postlarvae.

By quantifying evolutionary divergence using a simple mathematical model, Zwart et al. (2010) deduced that ORF23/24, but not ORF14/15, sequence variation correlates well with when a WSSV isolate was obtained compared to when WSD first emerged in shrimp in Taiwan, and not with geographical distance from Taiwan. The analysis suggested that the WSSV type that emerged in crayfish being farmed in China in 2006 was a descendent or relative of the virus type that emerged in penaeid shrimp farmed in East Asia in the early to mid-1990s. ORF23/24 deletion sizes found in the 4 Procambarus clarkii WSSV isolates examined here do not violate this hypothesis. Moreover, the intermediate-sized ORF23/24 deletions found amongst the $P$. clarkii WSSV isolates appear to be common now amongst WSSV isolates derived from penaeid shrimp (Tan et al. 2009, Dieu et al. in press), suggesting similar origins or mechanisms by which they have been disseminated amongst both penaeid and non-penaeid shrimp. It also implies that the original geographic spread of WSSV might have been associated with marked shifts in genome types. However, once established, genome structures amongst endemic WSSV populations become more stable (Zwart et al. 2010).

As the number and order of RUs within ORF75 might be a feasible marker to study the regional spread of WSSV, especially at smaller scales (Dieu et al. 2004, 2010), a categorizing system for RU genotypes was devised to assist in defining epidemiological relation- 
ships. Based on this RU assignment scheme, a first 9RU motif (a-L-b-c-d-c-M-c-e) was found to be shared between the reference WSSV-TH isolate and the TH96-II isolate, and another first 9-RU motif (a-L-b-c-d-c$\mathrm{M}-\mathrm{g}-\mathrm{h})$ was found to be shared amongst the isolates 08JS, WSSV-TW and WSSV-CN. In BLAST searches of GenBank, 1 ORF75 sequence submission (Acc. No. AF403004) from 2001 was found from a WSSV isolate originating from Singapore, which was identical in sequence to WSSV-CN. Thus, based on ORF75 genotypes in early isolates of WSSV, they can be divided into 2 groups that have either remained in East Asia or separated to South Asia, possibly through commercial aquaculture-related activities in East Asia and in concordance with similar data interpretations (Marks et al. 2005, Zwart et al. 2010). Based on its genotype similarity to the WSSV-TW and WSSV-CN isolates originating from the early 1990s, the 08JS Procambarus clarkii isolate might represent a relatively ancient isolate in mainland China. This result provided support for data on ORF14/15 and ORF23/24 variable regions suggesting that isolates $08 \mathrm{HB}$ and $09 \mathrm{HB}$ might be descendents of isolate 08JS. However, more data on early WSSV isolates are needed to validate this hypothesis.

As reported by Waikhom et al. (2006), RU numbers in ORF94 were found to vary following passage of a WSSV isolate through different hosts. Significant variation in the ordering and numbers of ORF94 RUs has also been observed amongst WSSV isolates collected in Thailand and Vietnam, without any obvious correlation with geographical location (Wongteerasupaya et al. 2003, Dieu et al. 2004). Similarly, ORF94 RU numbers in the 4 Procambarus clarkii WSSV isolates examined here varied substantially from 3 to 14 , suggesting that this marker might be suitable for differentiating closely related isolates.

It has also been suggested that the ORF125 variable region might be suitable for epidemiological investigations of closely related WSSV strains (Dieu et al. 2010). Here, a new ORF125 genotype (designated G) was detected in 3 of the 4 Procambarus clarkii WSSV isolates examined (08HB, 09HB and 08JS), and a second new genotype (designated F) was also found in isolate 08HB. It thus appears that WSSV isolate 09JS originated from a different lineage compared to the other 3 P. clarkii isolates.

In summary, the ORF75 RU genotypes identified to date, including those in the 4 Procambarus clarkii WSSV isolates examined here, are suggestive of WSSV types having become segregated into 2 groups since first emerging in shrimp in East Asia in the early to mid-1990s, with one remaining in East Asia and the other separating to South Asia. In addition, the nature of deletion sizes in ORF23/24 and ORF14/15 variable regions and differences in ORF125 RU genotypes have been identified as epidemiological markers useful for determining the origins and spread of WSSV in crayfish in China, and differences in ORF94 RU genotypes have been identified as having the potential to differentiate closely related isolates. Although only $4 P$. clarkii WSSV isolates were examined, sequence data on the variable regions provided evidence for WSSV becoming established in crayfish farms in China from penaeid shrimp being farmed in East Asia, for the occurrence of multiple introductions, and for isolates $08 \mathrm{HB}$ and $09 \mathrm{HB}$ originating from the isolate 08JS. The isolate 08JS also possessed sequences indicative of it being a close relative of the reference WSSV-TW isolate originating from shrimp farmed in Taiwan in the early 1990s, and isolate 09JS possessed sequences indicative of it being a close relative of the reference WSSV-CN isolate originating from shrimp farmed in China in the early 1990s. Moreover, the hypothesis proposed by Dieu et al. (2010) that the WSSV type now common in shrimp farmed in central Vietnam originated from WSSV-CN was supported by sequences determined for the P. clarkii WSSV isolate 09JS.

Acknowledgements. This research was supported by the Shandong Province Natural Science Foundation (ZR2009DM005), the National Public Benefit (Agricultural) Research Foundation of China (200803012, 201003070), the Foundation of Shandong Education Department (J07YG01) and the Open Fund of Key Laboratory of Marine and Estuarine Fisheries Resources and Ecology, Ministry of Agriculture.

\section{LITERATURE CITED}

Chang YS, Peng SE, Wang HC, Hsu HC and others (2001) Sequencing and amplified restriction fragment length polymorphism analysis of ribonucleotide reductase large subunit gene of the white spot syndrome virus in blue crab (Callinectes sapidus) from American coastal water. Mar Biotechnol 3:163-171

Chen SN (1995) Current status of shrimp aquaculture in Taiwan. In: Browdy CL, Hopkins JS (eds) Swimming through troubled water. Proceedings of the special session on shrimp farming. Aquaculture'95. World Aquaculture Society, Baton Rouge, LA, p 29-34

Chen LL, Wang HC, Huang CJ and others (2002) Transcriptional analysis of the DNA polymerase gene of shrimp white spot syndrome virus. Virology 301:136-147

- Dieu BTM, Marks H, Siebenga J, Goldbach R, Zuidema D, Duong TP, Valk JM (2004) Molecular epidemiology of white spot syndrome virus within Vietnam. J Gen Virol 85: 3607-3618

> Dieu BTM, Marks H, Zwart MP, Valk JM (2010) Evaluation of white spot syndrome virus variable DNA loci as molecular markers of virus spread at intermediate spatiotemporal scales. J Gen Virol 91:1164-1172

Dieu BTM, Vlak JM, Zwart MP (in press) Effects of extensive and intensive shrimp farming on the genetic composition of white spot syndrome virus populations. In: BondadReantaso MG et al. (eds) Diseases in Asian aquaculture. VII. Fish Health Section, Asian Fisheries Society, Manila 
Ding Z, Xue H, Xia A, Tang J, Liu L, Liu W (2008) Study on the WSSV prevalence in the cultured crayfish (Procambarus clarkii). J Nanjing Agric Univ 4:129-133

Du HH, Li WF, Xu ZR, Kil ZS (2006) Effect of hyperthermia on the replication of white spot syndrome virus (WSSV) in Procambarus clarkii. Dis Aquat Org 71:175-178

Du HH, Fu L, Xu Y, Kil Z, Xu Z (2007) Improvement in a simple method for isolating white spot syndrome virus (WSSV) from the crayfish Procambarus clarkii. Aquaculture 262:532-534

Guarino LA, Summers MD (1986) Functional mapping of a trans-activating gene required for expression of a baculovirus delayed-early gene. J Virol 57:563-571

Hossain MS, Chakraborty A, Joseph B, Otta SK, Karunasagar I, Karunasagar I (2001) Detection of new hosts for white spot syndrome virus of shrimp using nested polymerase chain reaction. Aquaculture 198:1-11

Kool M, Van den Berg PMMM, Tramper J, Goldbach RW, Valk JM (1993) Location of two putative origins of DNA replication of Autographa californica nuclear polyhedrosis virus. Virology 192:94-101

Li LJ, Yuan JF, Cai CA, Gu WG, Shi L (2006) Multiple envelope proteins are involved in white spot syndrome virus (WSSV) infection in crayfish. Arch Virol 151:1309-1317

Liang T, Ji H, Lian L, Wu T, Gu W, Wang W (2010) A rapid assay for simultaneous detection of Spiroplasma eriocheiris and white spot syndrome virus in Procambarus clarkii by multiplex PCR. Lett Appl Microbiol 51:532-538

Lightner DV, Redman RM, Poulos BT, Nunan LM, Mari JL, Hasson KW (1997) Risk of spread of penaeid shrimp viruses in the Americas by the international movement of live and frozen shrimp. Rev Sci Tech Off Int Epiz 16: 146-160

Marks H, Goldbach RW, Vlak JM, van Hulten MCW (2004) Genetic variation among isolates of white spot syndrome virus. Arch Virol 149:673-697

Marks H, van Duijise JJA, Zuidema D, van Hulten MCW, Vlak JM (2005) Fitness and virulence of an ancestral white spot syndrome virus isolate from shrimp. Virus Res 110: $9-20$

Moon CH, Do JW, Cha SJ and others (2003) Highly conserved sequences of three major virion proteins of a Korean isolate of white spot syndrome virus (WSSV). Dis Aquat Org 33:231-234

Pradeep B, Shekar M, Karunasagar I, Karunasagar I (2008) Characterization of variable genomic regions of Indian white spot syndrome virus. Virology 376:24-30

Richman LK, Montali RJ, Nichols DK, Lightner DV (1997) A newly recognized fatal baculovirus infection in freshwater crayfish. In: Proceedings of the American Association of Zoo Veterinarians 1997, Abstracts, p 262-264

Sánchez-Paz A (2010) White spot syndrome virus: an overview on an emergent concern. Vet Res 41:43-76

Tan Y, Xing Y, Zhang H, Feng Y, Zhou Y, Shi ZL (2009) Molecular detection of three shrimp viruses and genetic variation of white spot syndrome virus in Hainan Province,

Editorial responsibility: Jeff Cowley,

Brisbane, Queensland, Australia
China, in 2007. J Fish Dis 32:777-784

van Hulten MCW, Valk JM (2001) Identification and phylogeny of a protein kinase gene of white spot syndrome virus. Virus Genes 22:201-207

van Hulten MCW, Witteveldt J, Peters S, Kloosterboer N and others (2001) The white spot syndrome virus DNA genome sequence. Virology 286:7-22

Vijayan KK, Raj VS, Balasubramanian CP, Alavandi SV, Sekhar VT, Santiago TC (2005) Polychaete worms-a vector for white spot syndrome virus (WSSV). Dis Aquat Org 63:107-111

Waikhom G, Riji John K, Rosalind George M, Prince Jeyaseelan MJ (2006) Differential host passaging alters pathogenicity and induces genomic variation in white spot syndrome virus. Aquaculture 261:54-63

> Wang Q, White BL, Redman RM, Lightner DV (1999) Per os challenge of Litopenaeus vannamei postlarvae and Farfantepenaeus duorarum juveniles with six geographic isolates of white spot syndrome virus. Aquaculture 170: 179-194

> Wang Q, Poulos BT, Lightner DV (2000) Protein analysis of geographic isolates of shrimp white spot syndrome virus. Arch Virol 145:263-274

Wang ZF, He WX, Xu WJ (2007) Study on epidemic outbreak of disease of crawfish caused by WSSV. Chinese J Health Lab Technol 17:1397-1399

Wei J, Lu CP, Hong J, Yang CH (1998) Artificial infection of crayfish with the non-occluded shrimp virus. J Nanjing Agric Univ 21:78-82

Wongteerasupaya C, Pungchai P, Withyachumnarnkul B, Boonsaeng V, Panyim S, Flegel TW, Walker PJ (2003) High variation in repetitive DNA fragment length for white spot syndrome virus (WSSV) isolates in Thailand. Dis Aquat Org 54:253-257

Xu J, Fan YD, Zhou Y, Zeng LB (2008) PCR and nested PCR methods for detecting WSSV in Procambarus clarkii. Freshw Fish 38:52-55

Xu YX, Tang L, Zhang MY, Yuan SM, Zhu YF (2009) Physiology and attack-back research of white spot syndrome virus of Penaeus vannamei boom reared in fresh-water. J Suzhou Univ Nat Sci 25:81-83

Yang F, He J, Lin XH, Li Q, Pan D, Zhang XB, Xu X (2001) Complete genome sequence of the shrimp white spot bacilliform virus. J Virol 75:11811-11820

Zeng Y, Lu CP (2009) Identification of differentially expressed genes in haemocytes of the crayfish (Procambarus clarkii) infected with white spot syndrome virus by suppression subtractive hybridization and cDNA microarrays. Fish Shellfish Immunol 26:646-650

Zhu JZ, Lu CP (2001) Characterization of shrimp white spot syndrome virus (WSSV) infection in Procambarus clarkii. J Fish China 25:47-51

Zwart MP, Dieu BTM, Hemerik L, Valk JM (2010) Evolutionary trajectory of white spot syndrome virus (WSSV) genome shrinkage during spread in Asia. PLoS ONE 5: e13400

Submitted: March 1, 2011; Accepted: June 28, 2011

Proofs received from author(s): August 20, 2011 